ARTíCULOS DE INVESTIGACIÓN

\title{
O ensino jurídico e a dinâmica pedagógica: A aplicação da metodologia ativa no curso de direito da Universidade Federal do Acre, Campus Floresta
}

\author{
Educación legal y dinámica pedagógica: La aplicación de las metodologías activas \\ en un curso de derecho de la Universidad Federal de Acre, Campus Floresta
}

Legal education and pedagogical dynamics: The application of the active methodology in the law course of the Federal University of Acre, Campus Floresta

\author{
Fabiana David Carles \\ Universidade Federal do Acre, Brasil \\ Vitória Caroline Brandão da Costa Siqueira \\ Universidade Federal do Acre, Brasil \\ Enzo Matheus Freitas de Araújo \\ Universidade Federal do Acre, Brasil
}

\begin{abstract}
RESUMO Este artigo tem como objetivo analisar, brevemente, a importância do ensino jurídico com base na aplicação dos instrumentos da aprendizagem dinâmica e do desenvolvimento das capacidades lógicas do estudantes. Foi utilizado como exemplo deste processo de mudança nas atividades didáticas no campo das ciências do Direito, a recente alteração do modelo de instrução na disciplina de Direito Processual Civil na Universidade Federal do Acre, Campus Floresta. Verifica-se a urgência de modificar o ensino jurídico, de modo que supere o tecnicismo incorporado no fazer o Direito. Muitos ideais e interesses se manifestam na sociedade moderna e revelam um sistema jurídico em crise, o que torna necessária a busca de mecanismos para superá-la. Sendo assim, surge a importância de implementar metodologias ativas nos cursos de Direito para possibilitar que de fato, após sua formação acadêmica, os cidadãos estejam aptos para os deveres sociais enquanto juristas. A metodologia da pesquisa utilizada é de natureza qualitativa, baseando-se em análise bibliográfica.
\end{abstract}

PALAVRAS-CHAVE Ensino jurídico, crise metodológica, metodologias ativas, ensino dinâmico. 
RESUMEN Este artículo tiene como propósito analizar brevemente la importancia de la educación jurídica a partir de la aplicación de metodologias activas para el desarrollo de las habilidades lógicas de los estudiantes, a propósito del reciente cambio en el modelo educativo en la asignatura de Derecho Procesal Civil de la Universidad Federal de Acre, Campus Floresta. Existe una necesidad urgente de modificar la educación jurídica, a fin de superar el tecnicismo incorporado en la elaboración de leyes. Muchos ideales e intereses se manifiestan en la sociedad moderna y revelan un sistema legal en crisis, lo que hace necesario buscar mecanismos para superarlo. Por tanto, surge la necesidad de implementar metodologías activas en los cursos de Derecho para que los ciudadanos puedan desempeñar deberes sociales como juristas después de su formación académica. La metodología de investigación utilizada es de carácter cualitativo, basada en el análisis bibliográfico.

PALABRAS CLAVE Educación Legal, crisis metodológica, metodologías activas, enseñanza dinámica.

ABSTRACT This article aims to briefly analyze the importance of legal education based on the application of dynamic learning tools and the development of students' logical skills, being used as an example of this process of change in didactic activities in the field of the Right Sciences the recent change in the instructional model in the subject of Civil Procedural Law at the Federal University of Acre, Campus Floresta. There is an urgent need to modify legal education, in order to overcome the technicality incorporated in making law. Many ideals and interests are manifested in modern society and reveal a legal system in crisis, which makes it necessary to search for mechanisms to overcome it. Therefore, the importance of implementing active methodologies in Law courses arises to enable citizens to be able to perform social duties as jurists after their academic training. The research methodology used is of a qualitative nature, based on bibliographic analysis.

KEYWORDS Legal education, methodological crisis, active methodologies, dynamic teaching.

\section{Introdução}

O ensino jurídico repousa hoje sobre uma crise metodológica que se manifesta na perceptível presença de tecnicismos e métodos muito teóricos e pouco práticos. Por conseguinte, é importante analisar quais aspectos influenciaram diretamente para que a referida crise se instaurasse nas faculdades de Direito, visto que esta problemática atinge não somente o cenário brasileiro, mas o mundial. Para tanto, tornou-se necessário descrever de forma sucinta a trajetória histórica do ensino jurídico, desde sua criação, implementação e avalição acerca de sua função e qualidade no contexto mencionado. 
Há tempos, se verifica a insatisfação vivenciada por estudantes e profissionais do Direito quanto à ministração dos conteúdos em sala de aula, principalmente, no que diz respeito às técnicas de transmissão - a saber, por parte do docente -, e ao acesso qualitativo da perspectiva do acadêmico sobre conhecimento experimentado, bem como ao adequado desenvolvimento de sua capacidade de utilizá-lo para atender às demandas do mercado de trabalho.

Inúmeros são os fatores que corroboram diretamente para o avanço desta controvérsia. Alunos se revelam inconformados com o que a universidade oferece, seja por meio de um «adestramento» profissional ou com o amontoado de teorias e pouca prática no que condiz ao exercício do Direito. Professores manifestam o descontentamento com alunos desinteressados e a obrigação de seguir um currículo enciclopédico, de caráter evidentemente mecanicista, o que os impede de difundir conteúdos efetivamente duradouros no que tange ao aprendizado dos discentes. Todo este cenário torna-se ainda mais desastroso quando soma-se a ele o crescente número de instituições que se aglomeram e perpassam um sistema ineficaz de propagar o ensino jurídico, cujos objetivos visam à formação em massa, buscando o caráter quantitativo, e se distanciando, cada vez, mais do critério qualitativo de formação.

Ante o exposto, a proposta do presente estudo é evidenciar como a literatura contemporânea trata da aplicação das dinâmicas ativas no ensino jurídico, ao passo em que trata da utilização do formato de ensino mais ativo no curso de bacharelado em Direito, na Universidade Federal do Acre, Campus Floresta, em Cruzeiro do Sul, Acre. Para tanto, traçar-se-á um diálogo entre a forma de se conceber o «como»o ensino jurídico deve ser conduzido pelo docente, a fim de discutir e, posteriormente, implementar uma transformação consubstancial das metodologias aplicadas ao ensino jurídico. Com isso, pretende-se alcançar a raiz de formação dos currículos dos cursos de Direito e torná-los aptos a construir uma nova postura dos operadores, cientistas e juristas, contemplando assim, as novas exigências do mercado. Desta forma, verifica-se a necessidade da consolidar uma nova postura por parte dos dois principais atores da dinâmica da formação na seara do Direito, a saber, o docente e o discente.

O presente trabalho, inicialmente, discute o arcabouço teórico subjacente à estrutura de formação metodológica da concepção de modelo ideal de ensino jurídico em comparação àquele aplicado na realidade fática. Por fim, a título de contribuição, pretende-se apresentar as repercussões que a temática evidencia com base no exame da literatura, proporcionando um ambiente interlocutório à realização das reflexões desta problemática. 


\section{A influência das fases históricas das faculdades de direito no ensino jurídico atual}

Analisando as fases históricas das faculdades de Direito, Irti (2004), em «A formação do jurista», retorna seu olhar para o passado na busca de compreender o seu panorama atual. Segundo este, ao regressar cerca de dois séculos na história é possível identificar e distinguir três fases vivenciadas pelas mesmas: fase do saber, fase da antinomia e fase do fazer. A primeira ocorre no início do século XIX, baseada na fundação da universidade alemã, que posteriormente se tornou modelo para a ciência europeia. Esta fase é um reflexo da junção do Direito com as demais ciências teologia, medicina, filosofia -, na qual o saber jurídico não se distancia dos demais saberes, mas pelo contrário, trabalha em conjunto na tentativa de estabelecer um sentido unificado de sujeito no mundo.

Nessa primeira fase, as faculdades de Direito não se preocupavam com a atuação técnica e prática da referida ciência, mas somente com o ensino de seus fundamentos, ou seja, bastava ao discente compreender e analisar experiências jurídicas.

O exercício real não era considerado objeto a ser, ao menos, assimilado na universidade, já que este era de competência apenas dos tribunais. Nesse sentido, já se fazia evidente a distinção entre o conteúdo teórico abordado na faculdade de Direito e sua dissonância com as exigências de saberes dadas às necessidades práticas que derivavam da atuação desses profissionais. É fato que, mesmo nos dias atuais, a dicotomia ora descrita resta cristalizada mundialmente, reflexo de metodologias não eficazes que apenas enfatizam a necessidade de absorver o amontoado de leis e normas no decorrer do curso, mas pouco lembradas durante a atuação profissional. Dessa forma, torna os estudantes recém-formados em seres apáticos e pouco propensos a conseguir desempenhar, de forma satisfatória, os procedimentos necessários à resolução de conflitos inerentes à sociedade. Desta maneira, a didática do Direito dogmático, nas palavras de Mendonça e Adaid (2018: 820), seria o ensino

(...) relacionado com um Direito fechado ao questionamento, em que se aceita aquilo que está previamente determinado, oposto do enfoque zetético, que nomeia a dúvida como principal elemento da discussão. Dessa maneira, é possível fazer um paralelo entre o Ensino Jurídico com viés mais zetético e a influência do pensamento filosófico.

A segunda fase, já na segunda metade do século XIX, foi definida como técnicofuncional, experimentada em uma época de intensas mudanças e acontecimentos ao redor do mundo. Aquele século foi marcado pela revolução industrial e o nascimento das ciências sociais, bem como pela expansão da burguesia e do positivismo, fatores estes que modificaram a relação entre saber e fazer. Devido ao avanço do capitalismo, o trabalho tornou-se de importância crucial e corroborou para as transformações do 
conceito de mundo, decompondo o sentido unificado e universal de sujeito, explicitado no decorrer da primeira fase das faculdades de Direito. Ensino, ciência, instituições e todos os demais setores da sociedade precisavam se adaptar às exigências do mercado, o qual, passou a demandar não somente o conhecimento teórico, mas também a sua aplicação na realidade vivenciada.

Essas transformações foram as principais responsáveis pela introdução da práxis nas universidades, alterando a forma de propagar o ensino para que este fosse suficientemente prático, capaz de lidar com as novas percepções de atuação.

É diante disso que se firmou a antinomia saber e fazer; o primeiro revelava um Direito por meio de conhecimentos teóricos, o segundo, um Direito de técnicas e práticas. Cumpre ainda referir que a abordada antinomia, apesar de evidenciar a distinção do ensino jurídico teórico e prático, revelava também sua complementariedade quando da formação dos currículos dos cursos nessa fase.

Nesse momento se iniciou a fase do fazer, na qual o estudante deveria apreender apenas os conteúdos suficientes para que pudessedesempenhar sua função na divisão do trabalho.

Todo o restante do conhecimento que poderia ser usufruído foi deixado de lado, importando apenas a práxis que iria elevar a economia global no mundo capitalista. De forma simplista, o estudante escolheria apenas um campo de atuação profissional e se encaixaria nesta «bolha», não importando o aprofundamento de seus conhecimentos, desde que este já estivesse desempenhando sua função no mercado de trabalho. Nessa fase, o viés humanista da Universidade foi deixado de lado e a formação voltou-se apenas para a função instrumental de produção de conhecimento que fomente a mão de obra trabalhista. Assim, as Faculdades de Direito perderam sua função social e passaram a gerar apenas profissionais que atuavam nos setores do capitalismo.

É diante deste cenário, expresso pela concentração em sentidos opostos das habilidades introduzidas aos discentes, que se estabeleceu uma divisão pautada na separação de duas faces da mesma ciência, quais são, o saber de um lado e, do outro, o saber-fazer.Assim, originou-se um ambiente propício à disseminação da crise metodológica, que tem como arcabouço de existência o desencontro entre a teoria e a prática do Direito. Isto posto, aquele que passará pelo processo de formação, na seara do ensino jurídico, acabará inserido num ambiente «acadêmico» que lhe imporá escolher somente uma destas duas habilidades. Essa situação consolidará o processo de adestramento do estudante a apenas um específico campo de formação e atuação profissional.

A dinâmica do processo histórico-social-econômico acima descrito proporciona a verificação de causa e efeito existente entre os fundamentos que determinaram os sucessivos processos de alteração sob a óptica da função dos profissionais da área jurídica e, consequentemente, do modelo de formação mais adequado para esses sujei- 
tos. Portanto, verificou-se que são três as fases que serviram como fundamento para a existência de um modelo replicado pelas faculdades de Direito e que influenciam para que estas se encontrem da forma como estão atualmente.

Éimportante compreender quando nasce a concepção dos elementos fundantes do ensino jurídico, bem como as forças que os alteram e redimensionam. Ao chegarà fase de estabilização da ideia e sua implementação nas universidades - como forma de comprovar sua viabilidade prática e efetiva adequação mercadológica, pensadas a partir do desenvolvimento de habilidades e competências por aqueles que se submetem ao ora abordado processo de formação - verifica-se um vácuo entre a ideia e a realidade, para a qual os alunos estão sendo preparados. Este fato, acaba por expor a crise enfrentada pelo ensino jurídico e, de forma reflexa, a origem por uma nova demanda, qual seja a restruturação de um novo ideal de ensino jurídico para uma sociedade fundada em outra realidade. Logo, aplicar o velho ao novo reintroduz a pauta acerca da eficácia de formação e a denúncia de um sistema meramente artificial e infértil.

\section{As atuais faculdades de direito e o mundo globalizado}

Os paradigmas de adequação do «saber-fazer», já descritos anteriormente, ao ensino jurídico cristaliza que o «novo modo de pensar o direito» emergiu do ideal positivista que exerceu significativa influência em diversos países durante o século XIX, e impôs suas características na forma como o ensino jurídico era conduzido na reprodução da ideia de supremacia do Direito sobre as demais ciências. Seguindo esse viés, é cediço que a representação do saber está adstrita ao conhecer da lei e à sua aplicabilidade de acordo com a função - no sentido da teoria constituição orgânica da sociedade aristotélica - que desempenha na sociedade, sendo desnecessário analisar o contexto da produção da norma jurídica, fator que tornava o estudante e futuro profissional apenas um mero decorador e replicador de normas e leis.

No entanto, conforme foram ocorrendo mudanças - políticas, econômicas, sociais e culturais - ao redor de todo o mundo, esse cenário foi se alterando e, hoje, se tem um quadro de Ciências Sociais que engloba não somente o Direito, mas também ciências como a Sociologia, Filosofia, História, que interferem diretamente na forma como o conhecimento se estrutura. É em meio a essa interdisciplinaridade, que aos poucos, os conflitos presentes na sociedade vão conseguindo encontrar respostas às demandas existentes na contemporaneidade.

Há de se destacar, neste interim, que o avanço da sociedade frente à globalização e a rapidez com que a informação se dissipa no mundo criam oportunidades de intercâmbio de conhecimentos, possibilitando que tanto professores como alunos, que buscam corriqueiramente o aprimoramento de seus conhecimentos e habilidades, 
recorram a universidades de fora do país em que residem. Ao fazer isso, no entanto, estes se deparam com a obrigação de seguir padrões e pautas específicas de seus respectivos orientadores, pois só assim encontrarão espaço nas competitivas faculdades. É o que diz Falcão (2012: 98):

Nossos alunos, futuros professores, passam, então, um, dois ou cinco anos pesquisando temas, teses, teorias e métodos que se adequam muito mais à pauta do professor orientador do que à demanda brasileira interna ou globalizada. Corre-se o risco de haver, em nome de uma formação global, um sutil e não consciente processo de colonização cultural. Por motivos os mais inocentes possíveis, como a mera ausência de bibliotecas e bancos de dados especializados no Brasil, ou a disponibilidade de um orientador. Correm o risco de o mestrando se transformar em corredor de exportação de produtos estrangeiros. Este risco é evitável quando deles temos ciência.

Este é apenas um entre diversos outros exemplos que evidenciam o impacto da globalização no ensino jurídico, que poderia ser usufruída de forma positiva. Todavia, à medida que avançam as possibilidades de se profissionalizar ao redor do mundo, surgem problemáticas como esse "processo de colonização cultural», na qual o orientador impõe seus próprios princípios e afasta-se da demanda globalizada que poderia trazer significativamente mais produções e conhecimentos para aprimorar o ensino jurídico no mundo.

No entanto, há de se destacar uma possível alternativa para essa problemática, visualizada por meio da criação de escolas de Direito global. Um exemplo disto é a Escola de Direito da University of Cape Town (Cidade do Cabo). Assim, na tentativa de exemplificar o funcionamento desta, a diretora Pamela Schwikkard (2014: 18) concedeu entrevista para a Fundação Getúlio Vargas, na qual afirma:

Uma global Law school é aquela que oferece um currículo que habilita os estudantes de direito a verem um sistema jurídico nacional em particular como um componente de um esquema muito mais complexo de relações jurídicas globais. É também uma escola que dá aos estudantes acesso a habilidades e conhecimentos que irão permitir a eles praticar o direito em um contexto global.

Portanto, com o mundo globalizado, um dos desafios que surge no ensino do Direito é trazer não somente pautas que competem aos acontecimentos específicos de determinado país, mas tornar possível, diretrizes e metodologias que abrangem todo o cenário mundial. Assim, como afirmou Falcão «a globalização, longe de ser apenas competição econômica, cultural e militar entre nações, é também competição sobre como produzir, aplicar e distribuir Direito e justiça local e globalmente» (2014). 


\section{A crise no ensino jurídico}

As universidades de Direito enfrentam hoje uma crise generalizada no ensino jurídico (Vieira, 2012), visto que há uma frequente presença de dificuldades que retardam a boa formação acadêmica de seus alunos. Dentre estas, encontra-se o fato de os currículos disciplinares serem extensos em conteúdo, mas com curto prazo para serem repassados, causando a apreensão não só de estudantes, como também de profissionais que findam por desempenhar um trabalho inferior àquilo que estão preparados. Assim, o Direito vai definhando e perdendo espaço na produção de soluções para problemas reais da sociedade, como afirmou Dantas, ao ministrar a Aula Inaugural dos Cursos da Faculdade Nacional de Direito, em 1955:

É certo que na perda de poder criador da sociedade, a universidade tem a confessar grandes culpas. Se há problemas novos sem solução técnica adequada; se há problemas antigos, anteriormente resolvidos, cujas soluções se tornaram obsoletas sem serem oportunamente substituídas; se apareceram novas técnicas, que o nosso meio não aprendeu e assimilou; em grande parte isso se deve ao alheamento e à burocratização estéril das nossas escolas, que passaram a ser meros centros de transmissão de conhecimentos tradicionais, desertando o debate dos problemas vivos, o exame das questões permanentes ou momentâneas de que depende a expansão, e mesmo a existência da comunidade. (1955)

É notório que, apesar do trecho acima ter sido retirado de uma aula ministrada em 1955, a problemática em questão permanece atual, afinal as universidades ainda insistem em repassar didáticas tradicionais que pouco influenciam na resolução de conflitos da sociedade, o que desestimula os cidadãos a buscarem o Direito. Dessa forma, é necessária e inadiável uma reforma na educação jurídica, que valorize o estudante como criador do Direito e não somente aprendiz de normas e leis, que respeite a sabedoria do professor, deixando de impor conteúdos densos em aulas de 50 minutos que, na maioria das vezes, não possibilitam a apreensão e a produção de conhecimentos realmente eficazes. Como afirma Ghirardi (2012: 15), na sua obra «O Instante do Encontro»:

O ensino do direito é uma tarefa política - sobretudo em um país como o nosso em que o acesso ao terceiro grau é ainda restrito e desigual. Implica posicionar-se sobre a função social do ensino superior, isto é, sobre a própria razão de ser da universidade. Implica, portanto, fazer escolhas e posicionar-se frente a questões muito sérias: a universidade deve privilegiar o conhecimento especulativo, prioritariamente conceitual e abstrato, ou deve dar maior ênfase ao conhecimento aplicado, voltado a maximizar sua possibilidade de utilização prática?

Não obstante, Dantas (1955: 8) expõe o que, na sua concepção, é um dos principais problemas que agravam a crise metodológica instalada nas universidades ao redor do 
mundo. Segundo este, existe uma falsa percepção por parte das faculdades de que, ao obter o conhecimento teórico, o estudante estará apto para conseguir aplicá-lo na resolução de casos práticos. Todavia, isso torna ainda mais difícil alcançar uma verdadeira educação jurídica.

A didática tradicional parte do pressuposto que, se o estudante conhecer as normas e instituições, conseguirá, com os seus próprios meios, com a lógica natural do seu espírito, raciocinar em face de controvérsias, que lhe sejam amanhã submetidas. O resultado dessa falsa suposição é o vácuo que a educação jurídica de hoje deixa no espírito do estudante já graduado, entre os estudos sistemáticos realizados na escola e a solução ou a apresentação de controvérsia, que lhe exige na vida prática (Dantas, 1955: 8).

Diante disso, vale destacar que o ensino atual está disposto a buscar soluções eficazes que superem essa crise. Hodiernamente, o ensino é, em sua grande maioria, realizado de forma expositiva, seguindo padrões sistemáticos a que os ingleses costumavam denominar text system, trazendo soluções de casos prontos e impossibilitando que o discente analise e formule sua própria resolução. No entanto, o que Dantas (1955: 8) propõe é justamente o contrário, algo denominado case system, no qual o professor não dedica sua aula abordando uma única temática, mas leva casos a serem solucionados, levanta questões, obtém informações de diferentes pontos de vista e influencia o desenvolvimento do raciocínio dos alunos que serão futuros profissionais. Nas palavras dele:

A verdadeira educação jurídica, aquela que formará juristas para as tarefas da vida social, deve repetir esse esquema fundamental, colocando o estudante não em face de um corpo de normas, de que se levanta uma classificação sistemática, como outra história natural, mas em face de controvérsias, de conflitos de interesses em busca de solução. Só desse modo a educação jurídica poderá conceituar com clareza o seu fim, que é formar o raciocínio jurídico e guiar o seu emprego na solução de controvérsias. (Dantas, 1955: 8).

No entanto, é fato que as universidades de Direito existentes ao redor do mundo ainda carecem de realizar significativas alterações nas suas bases curriculares para que consigam alcançar essa «verdadeira educação jurídica» idealizada e proposta por Dantas. Afinal, será que mesmo após a conclusão do curso, os bacharéis em Direito recém-formados estarão aptos a atuarem na resolução de casos concretos e conflitos sociais? É justamente diante deste questionamento que se firmam as maiores necessidades de mudanças no ensino repassado dentro das salas de aula, para que, assim, o Direito possa voltar a se tornar uma Ciência reconhecida por seus feitos sociais e os juristas serem reconhecidos como cidadãos indispensáveis à promoção da justiça. É o que afirma Dantas (1955: 15), ao destacar: 
Precisamos levar o Direito ao tecido das relações sociais, reimpregnar dele os problemas que a sociedade submete ao controle de outras técnicas, como as que lhe são fornecidas pela Ciência Econômica e pela novel Ciência da Administração, de modo que o Direito não se alheie a qualquer problema social, e tenha sob sua orientação última todos os critérios engendrados para resolvê-los.

Outrossim, conforme salienta Giroux (2005: 3), os docentes tem papel fundamental no processo de superação da crise metodológica que hoje aflige as Universidades ao redor do mundo. Ele afirma:

Os educadores devem ser considerados intelectuais públicos que estabelecem a conexão entre idéias, tradições, disciplinas e valores críticos da esfera pública no seu dia a dia. Mas, ao mesmo tempo, os educadores devem assumir a responsabilidade de vincular seu trabalho a questões sociais mais amplas, perguntando o que significa treinar seus alunos para escrever textos políticos, perseverar diante da derrota, analisar problemas sociais e aprender, usar os instrumentos da democracia e fazer a diferença como agente social.

Diante o exposto, verifica-se que vários são os aspectos que corroboram para que a crise no ensino jurídico tenha se mantido no decorrer dos anos. No entanto, há de se afirmar que não foram poucas as tentativas de superá-la, principalmente, por professores da área, que trabalham diariamente buscando alternativas de proporcionar uma melhor formação para o corpo discente.

\section{A importância das metodologias ativas}

O cenário de crise que as universidades de Direito passaram a enfrentar representou, apesar das inegáveis dificuldades, o surgimento de um campo fértil para o debate de novas modalidades de ensino. A aplicação de instrumentos didáticos mais ativos podem ajudar a compreender e estimular a prática do Direito de maneira mais efetiva e harmoniosa para com os distintos aspectos da complexa realidade que cada profissional do campo das ciências jurídicas experencia. Como evidencia Venturi e Glitz,(2014: 132):

O ensino do direito no Brasil é marcado por uma abordagem exegética. Os alunos, por meio de aulas expositivas, aprendem conceitos e normas que são e poderão ser utilizados no dia-a-dia dos Tribunais, independentemente das funções que irão exercer (seja como advogado, juiz, promotor ou procurador). Ocorre, contudo, que cada vez mais as relações sociais tornam-se complexas e imprevisíveis, exigindo do jurista não apenas um conhecimento sistemático, mas também maior capacidade argumentativa. Além disso, o tradicional método de estudo empregado nas faculdades de Direito brasileiras é a parca preocupação com o desenvolvimento da capacidade de identificação de problemas, da capacidade de visualização da posição ocupada 
pelos envolvidos (alteridade), abstração das consequências sociais e jurídicas de cada um dos problemas e identificação de problemas não só teoricamente coerentes como, socialmente adequados.

Entretanto, tal processo de redescoberta do aprendizado na seara do Direito não se dá de forma linear e com frutos certos: é preciso haver da parte do pesquisador que presta-se a este feito a noção de que o entendimento da realidade sempre se dá em pequenas parcelas e que estas encontram-se em dinamismo constante. Desta maneira, cada fragmento e cada contexto exigem uma visualização distinta e igualmente atenta. Nesse sentido é que surgem os diversos projetos e estudos que visam a oferecer mudanças nas ferramentas metodológicas trabalhadas no ambiente acadêmico ${ }^{1}$.

Assim, Dantas (1955: 11) propõe que os discentes sejam preparados com uma mesclagem do princípio da formação geral e um princípio da formação especializada, na qual, o primeiro preparasse o acadêmico para desfrutar de conhecimentos relacionados a todas as áreas do Direito, e o segundo, estabelecesse um único viés temático para especialização e aprofundamento intelectual. Introduzir a citação, algo como, Fulano diz ainda:

A capacitação de quem deixa uma faculdade deve ser plena, abrangendo o exercício de todas as atividades profissionais de que o preparo jurídico é o pressuposto. Isso não exclui, entretanto, a possibilidade de assegurar-se ao estudante, por uma dosagem flexível dos currículos, o conhecimento mais aprofundado de determinadas partes do Direito. Teríamos, então, um currículo flexível, que permitisse, sem prejuízo da formação integral e da capacitação plena do futuro graduado, a sua aplicação maior a estudos de um ramo do Direito, que oferece no meio social possibilidades definidas de especialização (Dantas, 1955: 11).

Desse modo, os futuros profissionais da área estarão aptos a desenvolver não somente uma parte específica que se dedicaram a aprender, mas possuirão todo o panorama geral da produção e execução da norma jurídica. Sendo assim, com uma formação ampla, e a comunhão entre teoria e prática, os operadores do Direito poderão resgatar a fé nessa Ciência que, durante muitos períodos, foi colocada à prova, pois, conforme sugere Rodrigues (1988), teoria e prática não são dissociáveis e, somente com a integração de ambas, o estudante pode perceber o Direito nas relações sociais.

Nas palavras de Rodrigues (2005:43):

1. Neste ponto, é interessante lembrar do trabalho realizado por Streck (2007) - tratando principalmente e especificamente de seu texto «Hermenêutica e Ensino Jurídico em Terrae Brasilis» -, que observava, com profunda atenção, a importância da aplicação de uma metodologia ativa e uma hermenêutica filosófica na interpretação dos princípios normativos e constitucionais, com fins de superar as deficiências e insuficiências teóricas do discurso comum de ensino no contexto jurídico. 
A forma mais eficaz de construir-se um saber democrático sobre o Direito é fazêlo através de uma ciência que esteja comprometida com a vida e com a justiça social concreta e na qual não haja restrições à produção do conhecimento. Para isso, é necessária a constituição de um saber estruturado a partir de métodos e de paradigmas epistemológicos abertos. Os saberes fechados, estanques, unívocos, são perigosos e autoritários, transformando-se o ensino a eles vinculado em um conjunto de atos de violência simbólica. Apenas o ato pedagógico ligado a uma visão plural do mundo e comprometido com a construção de uma sociedade mais justa pode recuperar um espaço livre, democrático e não autoritário para o ensino do Direito.

É necessário construir um Direito que se aproxime de abordagens mais amplas, não como um mero sistema de normas, mas como Ciência que passa por inúmeros aspectos e contextos sociais, históricos, econômicos e culturais, que se transmite no sistema jurídico de leis ao mesmo tempo que se manifesta na interdisciplinaridade. Nisso, se apresenta a necessidade da aplicação de metodologias ativas que incentivem a versatilidade do ensino jurídico e a preparação dos discentes para atender às mais variadas demandas sociais, seja mediante o uso da teoria para a interpretação da lei, seja na resolução de casos concretos na prática.

A compreensão do que de fato torna uma metodologia ativa no campo do Direito converge com o entendimento do papel da universidade, tratando especificamente da formação dos indivíduos enquanto profissionais capacitados e devidamente constituídos para a aplicação eficaz dos conhecimentos adquiridos no nível superior. Isto significa dizer que a propositura de um novo formato metodológico, cuja natureza seja plenamente desembaraçada dos obstáculos recorrentes da prática jurídica na atualidade, deve necessariamente conter, em seu cerne, os aspectos do processo dialético de construção e aplicação das ciências jurídicas e, de forma mais geral, o movimento de conjugação do conhecimento com a realidade concreta, que produz, por fim, a experiência analítica no campo da vivência fática. ${ }^{2}$

\section{A teorização e implementação de uma nova proposta de metodologia ativa}

A necessidade de visualizar o ensino do Direito vinculado à realidade dos discentes - intermediado pela apresentação de metodologias que busquem um aprendizado direcionado para a autonomia do educando - proporciona o surgimento de estudos detalhados dos processos didáticos mais adequados a cada contexto específico. Em verdade, a crise na formação dos profissionais desse campo do conhecimento só encontra fim precisamente na percepção e enfrentamento das necessidades que o cenário fático exige para si. Nesse sentido - e à luz do que expõem os estudos acerca da crise do ensino do Direito - a profa. dra. Fabiana David Carles, docente do curso de bacharelado em Direito do Campus Floresta da Universidade Federal do Acre, desenvolveu uma metodologia de abordagem ativa na apresentação da disciplina de 
Processo Civil, fundamentando-se, precipuamente, no artigo 207 da Constituição Federal brasileira, que estipula que «as universidades gozam de autonomia didáticocientífica, administrativa e de gestão financeira e patrimonial, e obedecerão ao princípio de indissociabilidade entre ensino, pesquisa e extensão». (Brasil, Constituição, 1988, Capítulo III - Da Educação, da Cultura e do Desporto, art. 207).

O referido método consiste na aplicação de, basicamente, três etapas: teórica, prática e reflexiva. Estas foram executadas, efetivamente, na Oficina de Processo Civil, criada e aplicada com o intuito de apresentar uma nova modalidade de aprendizado adequada à realidade dos discentes, alvos do instrumento didático formulado pela docente. Durante a execução deste processo de aprendizagem, foram produzidas apostilas que, devido ao acompanhamento constante e orientação contínua da ministrante da disciplina, tornaram-se potenciais integrantes no acervo de materiais utilizados na exposição dos conteúdos. O método acima exposto se deu da seguinte forma:

- Parte teórica: Os alunos responsáveis por esta etapa, exerceram a função de analisar a doutrina estudada, filtrar os assuntos referentes ao conteúdo abordado na respectiva apostila, e utilizar recursos visuais e linguísticos, tais como resumos e tabelas, eficazes para torná-los compreensíveis a todas as pessoas que fizessem a leitura posteriormente.

- Parte prática: Nesse momento, foi necessário realizar a procura de casos concretos referentes ao assunto abordado, bem como buscar reflexos destes casos no cotidiano, aliando a teoria na prática do direito.

- Parte reflexiva: Configurada no final da apostila, esta etapa foi fundamental para analisar se os conteúdos foram compreendidos com o melhor aproveitamento possível no decorrer da leitura.Neste momento os discentes foram responsáveis por elaborar questões condizentes com o conteúdo tratado, com a finalidade de promover maiores reflexão e fixação dos assuntos, após a leitura.

No decorrer destas três fases, o que se objetivou foi a internalização do conteúdo por meio da análise de doutrinas, pesquisas de jurisprudências e casos concretos. Também se introduziu a oportunidade de elaboração de perguntas referentes ao vasto campo jurídico, dos assuntos abordados em sala e do cotidiano, gerando, por consequência, a interação direta dos alunos e da aplicação dos conhecimentos destes na apresentação de soluções às questões postas.

Ainda que este processo ainda esteja em andamento, os alunos já relatam a significativa melhora no aprendizado e desenvolvimento na disciplina de processo civil após a aplicação da oficina, que segundo estes supriu as lacunas entre a parte prática e teórica do direito. Relatam também que possibilitou a melhor capacidade de compreender os assuntos tratados na sala de aula. Interessante, neste ponto, notar como estas etapas contribuem para a formação de um raciocínio cíclico por parte dos estu- 
dantes que, devido à metodologia ativa construída de acordo com a realidade, podem compreender e aplicar de forma mais eficiente e intuitiva os conteúdos apreendidos. Desta maneira é que, um processo de aprendizagem especificamente adotado para suprir as peculiaridades deste grupo de acadêmicos, sustenta a compreensão de que é preciso avaliar o contexto fático em conjunto com o Direito que se leciona.

\section{Conclusão}

A crise no ensino jurídico se manifesta ao redor do mundo de forma complexa, de maneira que vem ganhando espaço desde a criação das primeiras Academias de Direito. Nesse sentido, o que objetivamos mostrar no decorrer deste trabalho foi, fundamentalmente, as raízes dessa crise e alternativas para superá-la. Deste modo, apresentamos exemplos de como as metodologias ativas são de significativa importância para a melhor propagação de um ensino jurídico eficaz.

Dessa forma, diante de alterações nas ferramentas metodológicas dentro das diretrizes curriculares dos cursos de Direito, será possível formar não meros replicadores de leis e conhecimentos teóricos, mas cidadãos capazes de identificar, com consciência, seus deveres sociais enquanto juristas. Assim como o fato é subsumido à norma, deve também o contexto específico - nas peculiaridades de seu tempo e complexidades do espaço que ocupa - ser observado sem desassociar-se do pleno ensino do Direito. Esta plenitude, por sua vez, revelar-se-á na apresentação de ferramentas aos discentes que, quando tornarem-se profissionais de verdadeira autonomia, poderão enfrentar as adversidades trazidas pela vivência profissional.

\section{Referências}

Dantas, San Tiago (1955). "A educação jurídica e a crise brasileira». Aula inaugural dos cursos da Faculdade Nacional de Direito. Disponível em https://www. santiagodantas.com.br/wp-content/uploads/A-Educa $\mathrm{C}_{3} \% \mathrm{~A}_{7} \% \mathrm{C}_{3} \% \mathrm{~A}_{3}$ Jur\% $\mathrm{C}_{3} \%$ ADdica-e-a-Crise-Brasileira.pdf.

FALCÃo, Joaquim (2012). «O futuro dos professores de Direito no ensino jurídico global», Cadernos FGV Direito Rio - Educação e Direito, no 7. Rio de Janeiro.

GHIRARDI, José Garcez (2012). O instante do encontro: Questões fundamentais para o ensino jurídico. Escola de Direito de São Paulo: Fundação Getulio Vargas.

Giroux, Henry (2005). «Qual o papel da Pedagogia Crítica nos estudos de língua e cultura? Uma entrevista om Henry A. Giroux». Revista Language and Intercultural Communication.

IRTI, Natalino (2010). «A formação do jurista», Cadernos FGV Direito Rio - Educação e Direito, no 4. Rio de Janeiro.

MendonçA, Samuel e Felipe Alves Pereira Adaid (2018) «Tendências teóricas sobre 
o Ensino Jurídico entre 2004 e 2014: busca pela formação crítica», Revista Direito FGV. 14 (3): 818-846.

Rodrigues, Horácio Wanderlei (2005). Pensando o ensino do direito no século XXI: Diretrizes curriculares, projeto pedagógico e outras questões pertinentes. Florianópolis: Boiteux.

-. (1988). Ensino jurídico: saber e poder. São Paulo: Acadêmica.

Schwikkard, Pamela (2014). «O que significa ser uma escola de Direito Global?», Cadernos FGV Direito Rio- Educação e Direito, no 9. Rio de Janeiro .

STRECK, Lenio Luiz (2007). «Hermenêutica e ensino jurídico em terrae brasilis», Revista da Faculdade de Direito UFPR. (46):27-50.

Venturi, Thais Pascoalotoe Frederico Eduardo Zenedin Glitz (2014). "A contribuição do método do estudo de casos e do exame de ordem na reformulação do ensino jurídico». Ensino jurídico e desafios contemporâneos. Curitiba: OABPR. (Coleção Comissões) 14:128-137.

VIeIRA, Oscar Vilhena (2012). «Desafios do ensino jurídico num mundo em transição: O projeto da Direito GV», Revista de Direito Administrativo. 261: 375-407.

\section{Sobre os autores}

Fabiana David Carles. Doutora em Direito. Professora de Direito da Universidade Federal do Acre (UFAC). E-mail: fabi.carles@gmail.com. (D) https://orcid. org/o000-0001-6875-7892.

Vitória Caroline Brandão da Costa Siqueira. Graduanda em Direito pela Universidade Federal do Acre (UFAC). E-mail: vitoria1caroline@hotmail.com. https://orcid.org/oooo-0001-9128-1917.

Enzo Matheus Freitas de Araújo. Graduando em Direito pela Universidade Federal do Acre (UFAC). E-mail: enzomatheus7@gmail.com. (D) https://orcid. org/o000-0003-2308-8271. 
